\title{
Stent-Assisted Coil Embolization of Ruptured Supraclinoid Blood Blister-Like Aneurysm of Internal Carotid Artery
}

\author{
Bo YU, Jian ZHENG, Yang HONG, LiangYu CHEN, Zhuo XI, Mingjun YU, Zhongyou QUE, Yunhui LIU \\ China Medical University, Shengjing Affiliated Hospital, Department of Neurosurgery, Shenyang, China
}

\section{ABSTRACT}

AIM: To report angiographic and clinical results obtained in patients with supraclinoid segment blood blister-like aneurysms (BBLAs) of the internal carotid artery treated with stent-assisted coil embolization.

MATERIAL and METHODS: A retrospective review of patients, who were treated for a ruptured supraclinoid BBLAs of the internal carotid artery (ICA) from 2004 to 2010, was performed. Clinical data, including hospital records, operative reports, and angiograms, were analyzed. Outcome was assessed using the modified Rankin scale (mRS).

RESULTS: Thirteen ruptured supraclinoid BBLAs in 13 patients were treated with stent-assisted coil embolization without any complication. Six patients recovered without any neurological deficits and three patients had mild neurological deficits (mRS 1 in one and 2 in two patients) due to late ischemic deficit. Three patients died of rebleeding and one died of intracranial infection after ventricular puncture for hydrocephalus.

CONCLUSION: In our experience, the natural history of supraclinoid BBLAs is dismal. Some of the lesions rebled after stentassisted coil embolization.

KEYWORDS: Stent-assisted coil embolization, Blister-like aneurysm, Internal carotid artery, Cerebral aneurysm, Intra-procedural rupture

\section{INTRODUCTION}

Blood blister-like aneurysms (BBLAs) have been reported to have an incidence of $0.4 \%$ (only 6 cases of 1484 patients (1). These aneurysms have high rates of intraoperative rupture when surgical clipping is attempted. Therefore, many treatment techniques have been proposed and reported in the literature.

Surgical treatment methods are encircling clip grafts, aneurysm wrapping, clip wrapping, trapping with or without an extracranial-to-intracranial bypass, and primary suturing. Endovascular treatment techniques include balloon-assisted coiling (17), stent-assisted coil embolization (8), covered stenting (8), overlapping stents (2), and parent vessel occlusion (15).
Although several different techniques have been proposed by leading centers across the world, no consensus has been reached on the safest treatment modality due to poor clinical outcomes (12,14-16). We present our experience in treating BBLAs with stent-assisted coil embolization.

\section{- MATERIAL and METHODS}

Patients with an aneurysmal subarachnoid hemorrhage (SAH) treated between April 2004 and April 2010 were retrospectively reviewed. Cases of BBLA of the supraclinoid internal carotid artery (ICA) were included in this study. Thirteen patients (eight women and five men) with a mean age of 52.5 years (range 34-73 years) were treated for a ruptured BBLA at acute stage (within 3 days). Patient demographic characteristics, aneurysm size and location, and functional outcomes are summarized in Table I. 
Yu B. et al: Stent-Assisted Coil Embolization

Table I: Clinical and Radiologic Details of Patients with BBLAs

\begin{tabular}{cccccccccc}
\hline $\begin{array}{c}\text { Patient } \\
\text { No. }\end{array}$ & Age/Sex & $\begin{array}{c}\text { H\&H } \\
\text { grade }\end{array}$ & Locations & $\begin{array}{c}\text { Neck/Height } \\
\text { Size }(\mathbf{m m})\end{array}$ & Stent & $\begin{array}{c}\text { Results } \\
\text { (Raymond class) }\end{array}$ & Rebleed & $\begin{array}{c}\text { Follow-up } \\
\text { (months) }\end{array}$ & $\begin{array}{c}\text { Outcome } \\
\text { (mRS) }\end{array}$ \\
\hline $\mathbf{1}$ & $63 / \mathrm{F}$ & $\mathbf{1}$ & Left & $6 \times 5$ & LEO & 3 & no & 8 & 0 \\
\hline $\mathbf{2}$ & $55 / \mathrm{M}$ & 3 & Right & $5 \times 3$ & Leo & 2 & On day 2 & No & Died \\
\hline $\mathbf{3}$ & $41 / \mathrm{F}$ & 2 & Right & $4 \times 3$ & Leo & 2 & No & 6 & 0 \\
\hline $\mathbf{4}$ & $40 / \mathrm{M}$ & 2 & Left & $3 \times 2$ & Leo & 1 & No & 14 & 2 \\
\hline $\mathbf{5}$ & $53 / \mathrm{M}$ & 4 & Right & $3 \times 2$ & Leo & 3 & No & No & Died \\
\hline $\mathbf{6}$ & $61 / \mathrm{F}$ & 3 & Right & $4 \times 3$ & Solitaire & 2 & No & 10 & 0 \\
\hline $\mathbf{7}$ & $40 / \mathrm{F}$ & 2 & Left & $4 \times 3$ & Solitaire & 3 & 4 hours later & No & Died \\
\hline $\mathbf{8}$ & $73 / \mathrm{F}$ & 3 & Right & $3 \times 3$ & Solitaire & 3 & No & 6 & 1 \\
\hline $\mathbf{9}$ & $56 / \mathrm{M}$ & 2 & Left & $4 \times 3$ & Solitaire & 3 & No & 6 & 0 \\
\hline $\mathbf{1 0}$ & $34 / \mathrm{F}$ & 3 & Left & $5 \times 2$ & Solitaire & 2 & On day 15 & No & Died \\
\hline $\mathbf{1 1}$ & $52 / \mathrm{F}$ & 2 & Left & $4 \times 3$ & Enterprise & 1 & No & 8 & 0 \\
\hline $\mathbf{1 2}$ & $56 / \mathrm{M}$ & 2 & Left & $4 \times 2$ & Enterprise & 1 & No & 6 & 0 \\
\hline $\mathbf{1 3}$ & $59 / \mathrm{F}$ & 3 & Left & $3 \times 3$ & Enterprise & 3 & No & 6 & 0 \\
\hline
\end{tabular}

H\&H: Hunt and Hess, BBLA: Blood blister-like aneurysm, mRS: Modified Rankin scale, M: Male, F: Female.

SAH was diagnosed by computed tomography (CT) scan or lumbar puncture if $\mathrm{CT}$ scan was normal. The clinical condition of the patients was evaluated by the Hunt and Hess $(\mathrm{H} \& \mathrm{H})$ grading system. Soon after the admission of the patient, complete four to six-vessel digital subtracted angiography (DSA) was performed to find out the origin of hemorrhage. Clinical and angiographic follow-ups were done at the same time. The functional outcome was assessed using the modified Rankin scale (mRS). The Raymond classification scale was used for the evaluation of aneurysm occlusion in the post-procedure and follow-up angiographies.

Patients were treated under general anesthesia using stentassisted coil embolization. A stent was positioned into the lumen of the parent vessel bridging the aneurysm with reconstruction of the vessel in all cases. Leo stents, Solitaire stents and, Enterprise stents were available for endovascular management. Subsequently, the aneurysm was coiled with platinum coils $(10,11)$.

The embolization was done under therapeutic heparinization with an activated clotting time of about 300 seconds. Patients were administered intravenous tirofiban after placement of the stent and then $75 \mathrm{mg}$ clopidogrel and $100 \mathrm{mg}$ aspirin the next day as an alternative, which was continued for 1 month along with aspirin for 6 months.

\section{RESULTS}

All patients were admitted in the acute phase of SAH (within 3 days post-SAH). One patient was Hunt and Hess Grade I, six were Grade II, five were Grade III and one was Grade IV.
The mean aneurysm size was $2.8 \mathrm{~mm}$ (range from 2 to 4 $\mathrm{mm}$ ) and the mean neck size was $4 \mathrm{~mm}$ (range from 3 to 5 $\mathrm{mm}$ ). There was no peri-procedural complication. On postprocedural angiograms, complete obliteration (Raymond 1) of the BBLA was achieved in 3 aneurysms. Raymond 2 occlusion (neck remnant) was observed in 4 aneurysms (Figure 1A-C) and Raymond 3 occlusion (base filling) was observed in 6 aneurysms. Three post-interventional bleedings were monitored during the period of 2 hours to 15 days. All the 3 aneurysms had filling of a residual base (2 Raymond Class 2 and 1 Raymond Class 3) on the post-procedural angiogram. One typical example is given in Figure 2A, B. At 7.8-month (range from 6-to 14-month) follow-up, 9 patients had achieved a favorable outcome (mRS 0-2). Four patients died, three died of re-bleeding and one died of severe intracranial infection after a ventricular shunt. The 3 patients had neurological deficits caused by late ischemic deficit, 2 of which experienced improvement at follow-up. A followup angiogram was performed in 9 patients and showed 5 Raymond class 1 aneurysms, 2 class 2 aneurysms and 2 class 3 aneurysms.

\section{DISCUSSION}

BBLA is a hemispheric bulge protruding from non-branching sites in the supraclinoid segment of the ICA. These aneurysms are located most frequently on the dorsal wall of the ICA. They may also be detected on the distal medial, superior, or anterior walls of the ICA $(12,15,16,19)$. They are often of small size with a fragile wall and a poorly defined broad-based neck. 

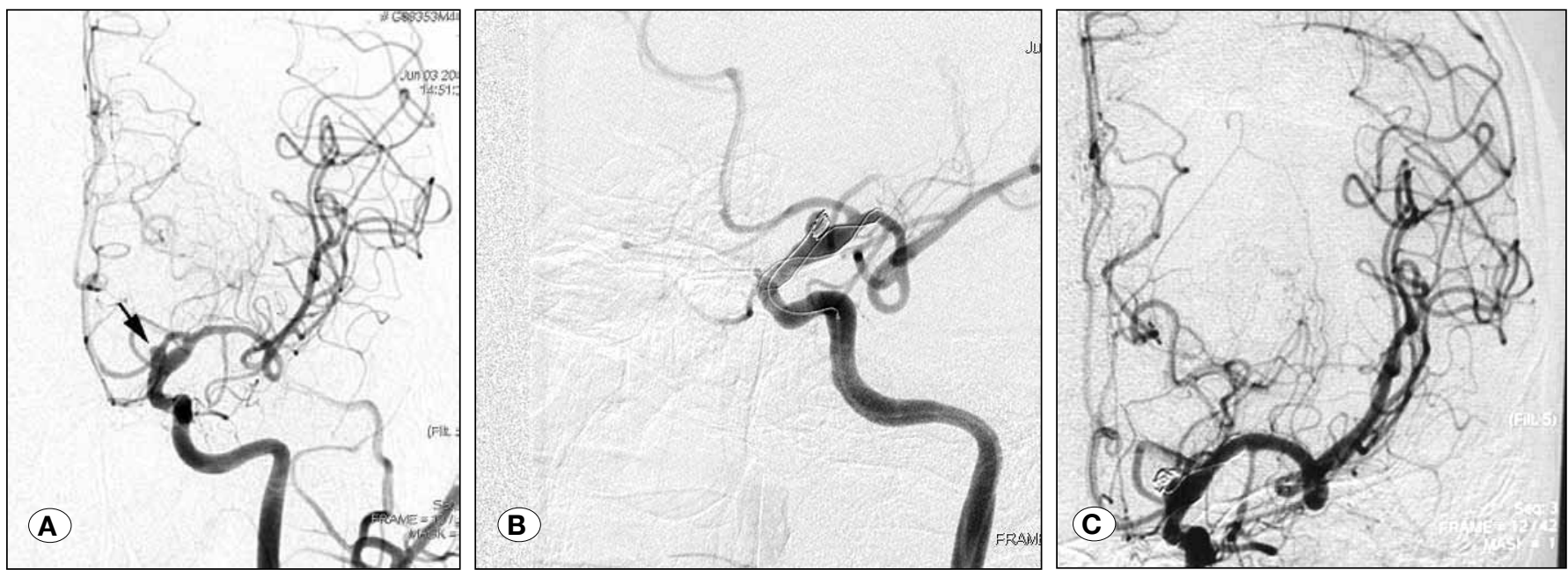

Figure 1: Illustrative Case 1. A) pre-embolization angiogram showed left ICA blister-like aneurysm (arrow). B) left ICA angiogram showed Leo stent-assisted coil embolization of the aneurysm. C) digital subtraction angiogram, left internal carotid injection, anteroposterior view, obtained following embolization of the "blister-like" aneurysm demonstrated improved obliteration of the aneurysm with a small amount of contrast filling in the neck region (Raymond class 2).
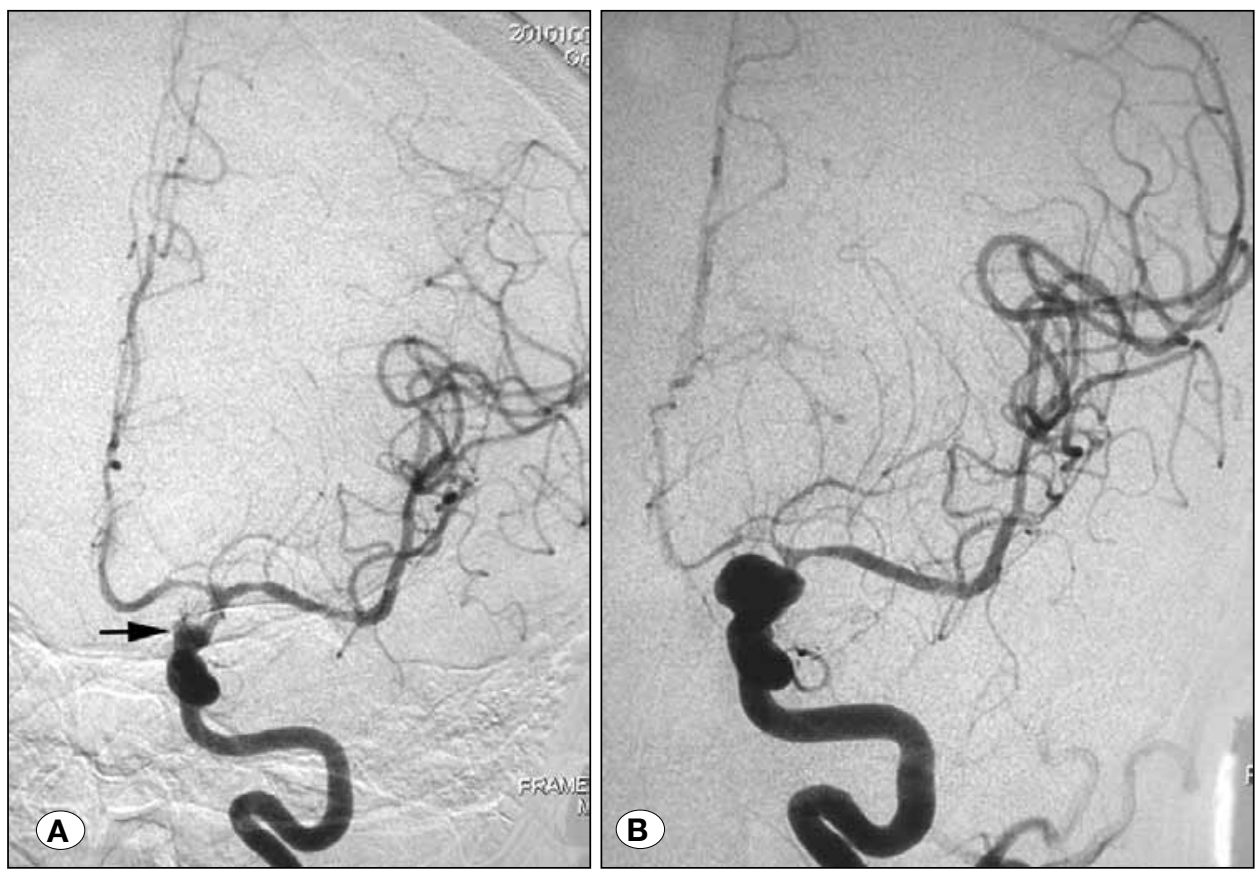

Figure 2: Illustrative Case 2.

A) Digital subtraction angiogram, left internal carotid artery injection, lateral view, obtained the day following the patient's admission. This study demonstrated a subtle dilatation on the medial aspect of the distal internal carotid artery (arrow). B) Digital subtraction angiogram, left internal carotid artery injection, anteroposterior view, obtained 5 days after diagnostic angiography. This study revealed moderately severe vasospasm of the distal internal carotid artery (arrow heads) and significant growth of the internal carotid artery aneurysm (arrow).

To date, the natural history of BBLA remains unclarified. Our experience showed a dismal natural history for this lesion. BBLA is known to increase in size and to change configuration into a saccular shape $(2,3,6,13)$. Given the characteristics of $B B L A$, direct clipping is challenging and the intraoperative and postoperative rupture rate is higher than the rupture rate observed for other types of saccular aneurysms $(3,9,12)$.

BBLAs have a focal wall defect without internal elastic lamina and media. The gap is covered with thin adventitia and fibrinous tissue $(4,9)$. Based on these features, BBLA is considered a "pseudoaneurysm" $(4,12,20)$.
The progression of a BBLA to a saccular lesion is usually secondary to organization and growth of the clot which is adjacent to the focal wall defect $(1,12)$. Kim et al. (6) reported a tiny vascular bulge from the ICA that grew into a saccular configuration on follow-up angiography. This is probably due to recanalization of a thrombosed aneurysm.

Various treatment methods have been suggested for BBLA such as wrapping, clipping, clipping on various wrapping material, and trapping with bypass. Some authors have proposed clipping on wrapping material as the best treatment method for ruptured BBLA $(12,16)$. This treatment method does not completely occlude the aneurysm. In addition, it 
does not prevent re-bleeding and re-growth of BBLA. This method may also be hazardous for branches and perforators. Direct clipping is also dangerous because of the high rate intraoperative and postoperative bleeding $(1,9,12,15,16,19)$.

Endovascular management also does not provide satisfactory results for $\operatorname{BBLA}(17,18,20)$. Endovascular coiling is potentially hazardous and should not be considered for the treatment BBLA because of the pathogenesis of these aneurysms. Recently, Fiorella et al. (2) reported good outcomes with Neuroform stents (Boston Scientific, Fremont, CA, USA) to reconstruct the ICA. Some authors reported coiling with the assistance of closed cell stents with their own limitations and complications $(5,7,8,10,11,17)$.

In previous reports, intraprocedural hemorrhage was observed in 2 patients and these patients died. Aneurysm regrowth was seen in three patients and a second treatment was performed in these patients $(7,8,12)$. These cases have stressed the importance of including the normal arterial wall beyond the wall defect during the complete reconstruction of ICA (12).

Short-term follow-up angiography may occasionally show a dramatic change in the case of BBLA in the conformation of the lesion (15). The profound weakness of the aneurysm wall may be responsible for the growth of aneurysm in the ensuing 7-12 days after the hemorrhage $(3,15)$. Sometimes, followup angiography may show an evolution of the aneurysm into a saccular appearance (15), as illustrated by Case 2 (Figure $2 \mathrm{~A}, \mathrm{~B})$. The reorganization of the blood clot covering a focal wall defect in the aneurysm may also result in the saccular appearance. In addition, vasospasm of the normal supraclinoid ICA relative to the aneurysm may accentuate the aneurysm on the follow-up DSA. Once the BBLA has been diagnosed, surgical and endovascular options can be considered for the treatment (15).

The limitations of our study were the small number of patients, retrospective design of the study and lack of statistical analysis.

\section{- CONCLUSION}

The natural history of supraclinoid BBLAs is dismal. Some of the lesions may rebleed after stent-assisted coil embolization.

\section{- REFERENCES}

1. Abe $M$, Tabuchi $\mathrm{K}$, Yokoyama $\mathrm{H}$, Uchino A: Blood blister-like aneurysms of the internal carotid artery. J Neurosurg 89:419-424, 1998

2. Fiorella D, Albuquerque FC, Deshmukh VR, Woo HH, Rasmussen PA, Masaryk TJ, McDougall CG: Endovascular reconstruction with the Neuroform stent as monotherapy for the treatment of uncoilable intradural pseudoaneurysms. Neurosurgery 59:291300, 2006

3. Ikeda H, Izumiyama H, Hirota N, Abe T, Matsumoto K: Angiographic documentation of de novo aneurysm-case report. Neurol Med Chir (Tokyo) 38:730-732, 1998
4. Ishikawa T, Nakamura N, Houkin K, Nomura M: Pathological consideration of a "blister- like" aneurysm at the superior wall of the internal carotid artery: Case report. Neurosurgery 40: 403-405, 1997

5. Kim BM, Chung EC, Park SI, Choi CS, Won YS: Treatment of blood blister-like aneurysm of the internal carotid artery with stent-assisted coil embolization followed by stent-within-a- stent technique: Case report. J Neurosurg 107:1211-1213, 2007

6. Kim JH, Kwon TH, Kim JH, Park YK, Chung HS: Internal carotid artery dorsal wall aneurysm with configurational change: Are they all false aneurysms? Surg Neurol 66: 441-443, 2006

7. Korja M, Rautio R, Valtonen S,Haapanen A: Primary treatment of ruptured blood blister- like aneurysms with stent-assisted coil embolization: report of two cases. Acta Radiol 49: 180- 183, 2008

8. Lee BH, Kim BM, Park MS, Park SI, Chung EC, Suh SH, Choi CS, Won YS, Yu IK: Reconstructive endovascular treatment of ruptured blood blister-like aneurysms of the internal carotid artery. J Neurosurg 110:431-436, 2009

9. Lee JW, Choi HG, Jung JY, Huh SK, Lee KC: Surgical strategies for ruptured blister-like aneurysms arising from the internal carotid artery: A clinical analysis of 18 consecutive patients. Acta Neurochir (Wien) 151:125-130, 2009

10. Lv X, Li Y, Jiang C, Yang $X$, Wu Z: Potential advantages and limitations of the Leo stent in endovascular treatment of complex cerebral aneurysms. Eur J Radiol 79: 317-322, 2011

11. Lv X, Li Y, Xinjian Y, Jiang C, Wu Z: Results of endovascular treatment for intracranial wide-necked saccular and dissecting aneurysms using the Enterprise stent: A single center experience. Eur J Radiol 81(6):1179-1183, 2012

12. McLaughlin N, Laroche M, Bojanowski MW: Surgical management of blood blister-like aneurysms of the internal carotid artery. World Neurosurg 74: 483-493, 2010

13. McNeely PD, Clarke DB, Baxter B, Vandorpe RA, Mendez I: Endovascular treatment of a "blister-like" aneurysm of the internal carotid artery. Can J Neurol Sci 27:247-250, 2000

14. Meling TR, Sorteberg A, Bakke SJ, Slettebo H, Hernesniemi J, SortebergWJ: Blood blister-like aneurysms of the internal carotid artery trunk causing subarachnoid hemorrhage: Treatment and outcome. Neurosurgery 108:662-671, 2008

15. Mitha AP, Spetzler RF: Blister-like aneurysms: An enigma of cerebrovascular surgery. World Neurosurg 74(4-5):444-445, 2010

16. Ogawa A, Suzuki M, Ogasawara K: Aneurysms at nonbranching sites in the supraclinoid portion of the internal carotid artery: Internal carotid artery trunk aneurysms. Neurosurgery 47:578583, 2000

17. Park JH, Park IS, Han DH, KimSH, On CW, KimJ-E, Kim HJ, Han $\mathrm{MH}$, Kwon OK: Endovascular treatment of blood blister-like aneurysms of the internal carotid artery. J Neurosurg 106:812819, 2007

18. Raymond J, Guilbert F, Weill A, Georganos SA, Juravsky L, Lambert A, Lamoureux J, Chagnon M, Roy D: Long-term angiographic recurrences after selective endovascular treatment of aneurysms with detachable coils. Stroke 34:1398-1403, 2003

19. Sim SY, Shin YS, Cho KG, Kim SY, Kim SH, Ahn YH, Yoon SH, Cho KH: Blood blister- like aneurysms at nonbranching sites of the internal carotid artery. J Neurosurg 105:400-405, 2006

20. Tanoue S, Kiyosue H, Matsumoto S, Yamashita M, Nagatomi H, Mori HJ: Ruptured "blister-like" aneurysm with a pseudoaneurysm formation requiring delayed intervention with endovascular coil embolization: Case report. Neurosurgery 101:159-162, 2004 